\title{
Measuring the Impact of Economic Stability and Remittances of Overseas Workers on Bank Deposits: the Case of Jordan
}

\author{
Dr. Amjad Qwader ${ }^{1} \&$ Dr. Ateyah Alawneh ${ }^{1}$ \\ ${ }^{1}$ Tafila Technical University-College of Business, Jordan \\ Correspondence: Dr. Ateyah Alawneh, Tafila Technical University-College of Business, Jordan \\ Received: January 31, 2017 \\ Accepted: February 15, 2017 \\ Online Published: February 28, 2017 \\ doi:10.5430/afr.v6n2p45 \\ URL: https://doi.org/10.5430/afr.v6n2p45
}

\begin{abstract}
This study aims at measuring the impact of economic stability represented by (Inflation rate, Economic growth) and remittances of overseas workers on bank deposits in Jordan during the period (2000-2015).

The study used the multiple linear regression method by the (E-views) program to study the impact of the independent variables on the dependent variables. Statistical analysis showed the presence of a statistically significant, positive correlation for both the rate of inflation and workers' remittances on current deposits, saving deposits and time deposits. The statistical analysis also showed that there is a statistically significant, negative correlation between economic growth rate on current deposits, saving deposits and time deposits.

The study reached a number of recommendations, most important is: the need for local banks administration to take into consideration the economic factors and variables, including inflation, economic growth and remittances of overseas workers, which directly affect the bank deposits in Jordan, study their evolution and forecast their future value to take various measures that will be positively reflected on the growth of bank deposits.

Another recommendation is the need for local banks administration to attract more remittances of overseas workers, through genuine and honest programs that provide benefits for overseas workers and the bank alike.
\end{abstract}

Keywords: Economic stability, Inflation, Economic growth, Workers' remittances, Bank deposits

\section{Introduction}

Financial resources play a vital role in economic development in any country. The availability of these resources leads to achieving growth in capital formation rate. One of these resources is optional savings that turn by time to investment projects that offer commodity and service products that satisfy the needs and desires of the community, which will be positively reflected on achieving the economic and social prosperity of the community.

The growing of savings requires providing channels and means that facilitate the flow of funds from the economic units that have surpluses of those resources to economic units that suffer a shortage of these resources. The most important mean is the banking system, which plays a key and vital role in the economic and financial systems; because of its positive impact on economic development through attracting sufficient financial savings and distributing them adequately in various investment fields. In the light of what the world witnesses of economic openness and liberalization of capital, the competition in the banking activities has intensified, which imposed a relentless pursuit towards achieving efficiency in the various activities, so they can survive and go on.

The main banking activities are affected by a group of both internal and external environmental factors, which decide the extent of continuation of this bank or that in exercising the banking business and growing in it.

Among the external environmental factors for banks, which could affect their activities, are the economic stability and remittances of overseas workers. Therefore, this study will try to measure the impact of economic stability and remittances of overseas workers on bank deposits in the case of Jordan.

\subsection{The Importance of the Study}

The importance of this study emerges from the fact that it adds new evidences on the extent of the impact of economic stability represented by (the rate of inflation, economic growth), and remittances of overseas workers on bank deposits combination. 
A lot of information available on this correlation is in fact experiences of foreign countries, which are very different in their reality from the Arab countries. And this makes the results of this study realistic for the Arab States, to contribute in the enrichment of knowledge and additional information for those interested in banking affairs in understanding the nature of this correlation.

\subsection{Objectives of the Study}

This study aims at achieving the following goals:

1- Identify the impact of economic stability represented by variables (inflation rate, economic growth rate) and remittances of overseas workers on the current deposits in Jordanian banks.

2- Identify the impact of economic stability represented by variables (inflation rate, economic growth rate) and remittances of overseas workers on saving deposits in Jordanian banks.

3- Identify the impact of economic stability represented by variables (inflation rate, economic growth rate) and remittances of overseas workers on time deposits in Jordanian banks.

4- Propose some recommendations that can contribute to the growth of bank deposits in Jordanian banks.

\subsection{The Problem of the Study}

The problem of the study is represented in the lack of knowledge of the impact of economic stability represented by (the rate of inflation, economic growth), and remittances of overseas workers on bank deposits in Jordanian banks.

This problem can be illustrated in the following question:

Is there an impact of economic stability represented by (the rate of inflation, economic growth), and remittances of overseas workers on current deposits, saving deposits and time deposits in Jordanian banks?

\subsection{Hypotheses of the Study}

First hypothesis: there is a statistically significant, negative correlation between inflation rate and current deposits in Jordanian banks.

Second hypothesis: there is a statistically significant, positive correlation between economic growth rate and current deposits in Jordanian banks.

Third hypothesis: there is a statistically significant, positive correlation between remittances of overseas workers and current deposits in Jordanian banks.

Fourth hypothesis: there is a statistically significant, negative correlation between inflation rate and saving deposits in Jordanian banks.

Fifth hypothesis: there is a statistically significant, positive correlation between economic growth rate and saving deposits in Jordanian banks.

Sixth hypothesis: there is a statistically significant, positive correlation between remittances of overseas workers and saving deposits in Jordanian banks.

Seventh hypothesis: there is a statistically significant, negative correlation between inflation rate and time deposits in Jordanian banks.

Eighth hypothesis: there is a statistically significant, positive correlation between economic growth rate and time deposits in Jordanian banks.

Ninth hypothesis: there is a statistically significant, positive correlation between remittances of overseas workers and time deposits in Jordanian banks.

\subsection{The Variables of the Study}

\subsubsection{Independent Variables}

The rate of inflation (INF): it is the continued rise in the general number of prices, not the prices. The inflation is a relative change of the index number of the prices. The Inflation rate can be measured through the following equation:

$$
\mathrm{INF}=\frac{\left(\mathrm{CPI}_{\mathrm{t}}-\mathrm{CPI}_{\mathrm{t}-1}\right)}{\mathrm{CPI}_{\mathrm{t}-1}} * 100
$$


INF: inflation

\section{$\mathrm{CPI}_{\mathrm{t}}$ : the index number of the consumer prices for the current year. \\ $\mathrm{CPI}_{\mathrm{t}-1}$ : the index number of the consumer prices for the previous year.}

Economic growth rate (GDPG): is defined as the increase achieved in the community production on the long term.

Workers' remittances (REM): are defined as the process of transferring funds by a foreign worker to his homeland. They play a significant and increasing role in the economies of countries and economic growth. They are obtained from the statistical bulletin of the Central Bank.

\subsubsection{The Dependent Variables}

- Current deposits (Demand deposit): They are the money deposited by individuals and organizations in the banks, where they can be withdrawn as whole or any amount of them at any time, within the limits permitted by the bank's balance.

The current accounts have conditions in order to be used, where their owners can deposit money in cash, vouchers, withdrawals or checks, where the bank collects them on their behalf

- Saving deposits: They are a saving pot, found to encourage small savers to develop their saving awareness and give them the opportunity to take advantage of these deposits, especially those with limited income. The owners of these deposits can withdraw, deposit or transfer from the saving deposit, to be proved in the bankbook, and must be adopted by signatures of the bank on this book (Mashharawi, 2007).

- Time deposits: known as money deposited by the customer in the bank without requesting it before the expire of a particular date. For the bank, the advantage of these deposits is that they are not associated with any risk of being withdrawn as in the case of the demand deposits, therefore, the banks reward these deposits by granting their owners benefits that are higher than the previous ones (Alman , 2010).

\section{The Methodology}

Three models of multiple linear regression will be used to study the impact of economic stability and remittances of overseas workers on bank deposits in Jordanian banks as following:

The first model: the multiple linear regression model will be adopted, with using the (E-views) program, to study the effect of the independent variables on the current deposits in Jordanian banks, as in the following model:

$$
=\mathrm{f}(\mathbf{I N F}, \text { GDPG }, \text { REM }) \text { DD }
$$

DD: the value of current deposits in Jordan, per million Dinar during the year $t$.

INF: inflation rate in Jordan during the year $\mathrm{t}$.

GDPG: Economic growth rate in Jordan during the year t.

REM: the value of remittances of overseas workers in Jordan per million Dinar during the year $\mathrm{t}$.

Accordingly, the multiple regression equation can be written according to the following formula:

$$
\mathrm{DD}=\mathrm{a}+\mathrm{B} 1 \mathrm{INF}+\mathrm{B2} \text { GDPG + B3REM + E }
$$

The B1, B2, B3 are the regression coefficients for independent variables, that through their signals, the direction of the correlation between the independent variables and the dependent variable can be determined.

The second model: the multiple linear regression model will be adopted, with using the (E-views)program, to study the impact of the independent variables on saving deposits in banks in Jordan, as in the following model:

$$
\mathrm{SD}=\mathrm{f}(\mathrm{INF}, \mathrm{GDPG}, \mathrm{REM})
$$

Whereas:

SD: is the value of saving deposits in Jordan per million Dinar during the year $t$.

Accordingly, the multiple regression equation can be written according to the following formula:

$$
\mathrm{SD}=\mathrm{a}+\mathrm{B} 1 \mathrm{INF}+\mathrm{B} 2 \mathrm{GDPG}+\mathrm{B} 3 \mathrm{REM}+\mathrm{E}
$$

Since the B1, B2, B3 are the regression coefficients for independent variables, that through their signals, the direction of the correlation between the independent variables and the dependent variable can be determined. 
The third model: the multiple linear regression model will be used, with using the (E-views ) program, to study the impact of the independent variables on time deposits in banks in Jordan, as in the following model:

\section{TD $=$ f $($ INF, GDPG, REM)}

TD: is the value of time deposits in Jordan per million Dinar during the year $t$.

Accordingly, the multiple regression equation can be written according to the following formula:

$$
\text { TD = a + B1 INF + B2 GDPG + B3REM + E }
$$

Since the B1, B2, B3 are the regression coefficients for independent variables, that through their signals, the direction of the correlation between the independent variables and the dependent variable can be determined.

\subsection{Determinants of the Study}

The time horizon of the study extends from the year 2000 to 2015. It is the period during which the Jordanian public shareholding companies were obliged to disclose the cash flows after the issuance of instructions No. 1 of 1998, which are related to the disclosure requirements for companies listed in the Amman Stock Exchange, which helped in calculating the variables of the study. The subject of this study is confined to the banks operating in Jordan, whether the national or foreign ones.

\subsection{The Community of the Study}

The community of the study consists of the Jordanian banking system, that includes the national and foreign banks operating in Jordan, and they are (25) banks.

\subsection{The Study Approach}

The analytical method and the appropriate statistical methods will be adopted to deal with the data and extract statistical indicators and ratios to reach the goal of the study.

\subsection{The Study Sources}

Primary sources: the annual reports of the Central Bank of Jordan and the Jordanian Department of Statistics for the years (2000-2015).

Secondary sources: newsletters, journals, and previous studies related to the study.

\subsection{Theoretical Framework and Previous Studies}

Deposits play a prominent role in the economic and social development process. They represent a key factor in providing investors with the money they need to carry out their investments, thereby, increase production, reduce unemployment rates, fulfill the basic needs of the community and reduce the deficit in the balance of trade in addition to other economic and social benefits.

Regarding bank deposits in Jordanian banks, they have witnessed a remarkable development in their value, rising from (8.224.5) billion dinars in 2000 to (32.598.5) billion dinars in 2015. The largest share was for time deposit accounts by $(72.1 \%)$ of the total in 2000 , and $(55.5 \%)$ in 2015 . While the bank deposits of demand accounts gained $(16 \%)$ of the total in 2000 and $(5.30 \%)$ in 2015 . The share of the saving deposit accounts reached (11.8\%) in 2000 and (14\%) in 2015 (Central Bank, various editions).

The bank deposits are affected by a number of economic factors, and this is still the focus of great interest by those concerned in banking affairs as shareholders, lenders, bank administration, researchers and others, in order to determine the extent of the link between the bank deposits and the economic factors. The impact of these factors varies as some affect positively while others affect negatively on the bank deposits.

Among these factors, which the study tried to cover and look into their impact on bank deposits, are:

\section{First: Economic stability represented by (inflation rate, economic growth)}

1- Inflation rate: Economists have disagreed in determining the impact of inflation on saving behavior in general, and in the demand for bank deposits in particular.

Some of those interested believe that inflation and what it causes of deterioration in the purchasing power of money create an atmosphere that relatively helps in increasing the consumption, because the cost of retaining cash increases with the rise of inflation, which undermines the individual's desire in saving in general and makes him lose his direction towards saving instruments, offered by commercial banks and other saving institutions (Al-Zubeidi 2000, 159). 
Also, high inflation rates and what they cause of a decline in the real interest rate on the deposit will push individuals to invest in different assets, in order to avoid the deterioration of the real value of their cash accounts.

In contrast, some of those concerned review and confirm that inflation and its rising rates increase the saving and the demand for banking channels, and perhaps the reason is that inflation creates a sense of some uncertainty and pessimism about the future, which increases response and encourages saving. That is called precautionary saving (Al-Zubeidi 2000, 159 ).

Accordingly, depositing money in banks by money holders depends, to a large extent, on the efficiency that can be realized from the deposit process, through affecting the profit rate earned by depositors. The tendency to deposit rises with increased profit opportunities and rates. However, the deposit process decreases with the drop of profit opportunities.

By examining the developments in inflation rates in Jordan during the study period, they rose from ( $0.7 \%$ ) in 2000 to about (13.9\%) in 2008, and then began to decline until they reached (3.5\%) in 2015 (the Central Bank, various editions).

2- Economic growth rate: (Jebali, 2015) indicates that there is a positive circular correlation between economic growth and saving. An increase in saving leads to an increase in growth, and an increase in growth leads to an increase in saving.

(Marar, 2016) sees that the high economic growth indicators work on raising the income levels of individuals as well as their levels of education, and then generate a higher demand for banking services, either to deposit savings or demand for loans for investment.

Accordingly, the economic growth can be a factor of stimulation and mobilization of capitals, by pushing them towards depositing, where there is an opportunity to gain profit, as there may be a rise in the real rate of interest earned by depositors, or pushing the capitals towards investment to get a rate of return higher than the one obtained by depositors in case of deposit.

As for the developments in economic growth rates in Jordan during the study period, they rose from (3.8\%) in 2000 to about (27.9\%) in 2008, and then began to shrink until it reached (4.6\%) in 2015 (the Central Bank, various editions).

\section{Second: Remittances of overseas workers}

The subject of remittances of overseas workers gained a great interest by the planners and makers of economy-policies in addition to researchers and those interested in economic affair because they constitute a major financial resource for the economy.

The remittances of overseas workers have many positive and negative economic and social effects. On the positive side, the workers' remittances can contribute to activating and developing the investment environment, increasing reserves of hard foreign currency, supporting the balance of payments, increasing the amount of saving as a result of raising incomes, that it was originated from, reducing poverty, improving education and health side and solving part of the problem of housing through the revitalization of the business of buildings and land.

On the negative side, these remittances may contribute to increasing inflation rate caused by increased liquidity, trading in land and real estate and importing luxury goods (Al-Gazaw, 2013).

Also, foreign remittances have a negative impact on the economic growth in the countries receiving such transfers on the long term, by taking into account the rise in the migration of skilled workers from countries receiving remittances, searching for higher incomes.

Speaking about the remittances of Jordanians working abroad, they constitute one of the most important external financial flows to Jordan, which have contributed to boosting the Jordanian economy, strengthening the reserves of the Kingdom of foreign currencies and enhancing the living standards of the Jordanian citizen (Saydam, 2007).

These transfers have seen a remarkable development in value, rising from ( 1.3) billion JDs in 2000, which is (21.8\%) of the Gross Domestic Product GDP, to (3.8) billion JDs in 2015, which is ( $10.1 \%$ ) of GDP (the central bank, various editions).

The flow of foreign remittances to Jordan can contribute to encouraging competition in the local banking sector, which leads to reducing the costs of transferring those money, diversification of banking services and improving their quality. This will also lead to increasing the volume of bank deposits and increasing the domestic banking credit 
provided to the investors, which will be positively reflected in activating the investment environment of the Jordanian economy and improving the living standards of the Jordanian citizen.

\section{Previous studies}

- (John et al. 2001) This study focused on examining the effect of inflation rate on the financial sector and stock market activity. Results of the study indicated that there is a negative correlation, with an economic importance, between inflation and both of the development of the banking sector and the activity of the stock market.

- (Adam, 2012) This study aims at identifying the factors that affect the bank deposits in Sudan during the period (1982-2010). The study reached several conclusions, including: there is a positive correlation between the size of the demand for bank deposits and GDP, there is a positive correlation between the size of demand for bank deposits and the size of the bank financing.

In light of these results, the study provided some recommendations, most important is facilitating bank financing for various economic sectors, working on developing the demand for bank deposits model by raising the number of variables used in the study model in addition to increasing the period of time used in the model.

- (Erna and Ekki, 2004) The aim of this study is to identify the factors that affect the deposits of Mudaraba in Indonesia using the common integration and econometrics style, from 1993 - 2003. It concluded that there is a positive effect for the number of branches of the Islamic Bank, the rate of participation in profits and the interest rates on the size of Mudaraba deposits.

- (Saeed, 2006) This study aims at forming a proposed model for the analysis of bank deposits generally to determine the planning and regulatory indicators necessary in the banking business as a step that can be followed by programming that on computer, and then the analysis process becomes an automatic mechanism.

The study reached several conclusions, most important is the drop of volume of deposits as one of the bank sources of funds which come in second place after loans. Deposits formed ( 46\%), while the loans formed ( $47 \%$ ) of the size of the bank's funding sources.

The study also found that combination of the bank uses is not good, due to the predominance of the bank cash that formed $(71 \%)$ of those uses, while the investment banking facilities were very marginal.

- (Hamad, 2009) This study aimed at demonstrating the impact of the indirect monetary policy on interest rates of commercial banks during the period (1993-2007). The study concluded that there is a statistically significant, negative impact for the size of rediscount facilities and money supply on interest rates at commercial banks .It also found that there is a significant and positive impact for open market operations and the compulsory reserve on interest rates of commercial banks.

- (Rafiee \& Neghabi, 2013) This study aimed at identifying the factors that affect the bank deposits during the period from 2010 to 2012. The most important results of the study indicate that the ratio of bank deposits is negatively correlated with the US dollar exchange rate and the rate of growth of the banking industry. And that the ratio of bank deposits is positively associated with the growth of the Euro exchange rate.

- (Ojeaga \& Odejimi, 2014) This study aimed at measuring the impact of interest rates and the income average on saving behavior of the customers of the Nigerian banking sector. The most important results indicate that the interest rates and the income average positively affect the bank deposits.

- (Valahzaghard \& Kashfi, 2014) This study aimed at measuring the impact of GDPG, the depth of the financial market, the rate of inflation, the number of bank branches as well as the interest charged by the bank's clients on bank deposits in Iran, during the period 2006-2011. The results of the regression analysis showed that there is a significant and positive correlation between GDPG, financial market depth, rate of inflation and the number of branches of the bank on bank deposits.

-(Otu Larbi \& Peter, 2015) This study aimed at testing the effect of variables at the macroeconomic level on bank deposits in Ghana, during the period of 2000 - 2013. The most important results of the study indicate that there is a negative effect of the rate of inflation and money supply growth on bank deposits in Ghana.

\section{What distinguishes the current study?}

This study is distinct from previous studies due to the following points:

- It is one of the few studies in the Arab world and the first in Jordan, according to the knowledge of the researchers, that attempted to study the correlation between economic stability, represented by (the inflation rate, economic 
growth) and remittances of overseas workers son one hand, and bank deposits (current, saving, time) on the other hand.

- It is one of the few studies on the international level, according to the knowledge of the researchers, that attempted to study the effect of economic growth on bank deposits. Most studies, related to this subject, had focused on the impact of bank deposits on economic growth, noting that there is a circular correlation between economic growth and bank deposits.

- It is the first study, according to the knowledge of the researchers, which used the multiple linear regression method, with the help of the (E-views) program, to study the effect of the independent variables (economic stability, and workers' remittances) on the dependent variable (bank deposits).

\section{The Statistical Analysis of the Study}

- Estimating and Assessing the first regression model: the multiple linear regression method was used to estimate the impact of the independent variables on the current deposits (DD) in Jordanian banks, with the help of the (E-views) program. The results of the estimation came as following:

\section{First, Estimating the first regression model}

Table 1. Results of estimating the liner function of the first multiple regression model

\begin{tabular}{llll}
\hline Variable & Coefficient & t- Statistic & Prob \\
\hline$\Delta$ INF & 106.7880 & 1.813174 & 0.0999 \\
GDPG & -181.9374 & -3.396135 & 0.0068 \\
REM & 5.859653 & 9.150853 & 0.0000 \\
C & -4491.427 & -3.838153 & 0.0033
\end{tabular}

\section{Source: prepared by researchers with the help of the E-views program}

According to Table (1), the results of estimating the regression model were as following:

Adjusted R-Squared: $86 \% \quad$ R-Squared: $=\% 89 \quad \mathrm{~F}=28 \mathrm{D}-\mathrm{W}=1.40 \mathrm{n}=16$

From Table (1) above, you can notice that the independent variable (INF) is significant at a significance level of $10 \%$. While, the two variables (GDPG, REM) are significant at a significance level of 5\% .

\section{- The estimating equation for the first model}

DD = -4491.427 + 106.7880 $\Delta$ INF -181.9374 GDPG + 5.859653REM

\section{-Second: Assessing the first regression model}

1. Assessing the model according to economic criteria: the second column of Table (1) (Coefficient), which contains the assessed values of parameters, illustrates the following:

- The value of the fixed (C) equals $(-4,491.427)$, the signal of self-assessed current deposits is minus.

- The value of the inflation rate coefficient (INF) equals (106.7880), a positive signal, and is consistent with the economic and financial literature.

- The value of the economic growth rate coefficient (GDPG) equals (181.9374-), a minus signal, which is inconsistent with the economic and financial literature.

- The value of remittances from workers abroad coefficient (REM) equals (5.859653), a positive signal, which is consistent with the economic and financial literature.

2. Assessing the model according to the statistical standard:

It is clear from this model that the coefficient of determination is (Adjusted R-Squared: 86\%), which means that changes in the independent variables together explain about (89\%) of the changes of the dependent variable. While the value of (F-) statistic reached (28), and with Prob significance level, its value reached zero, meaning that the model is statistically significant.

The Darben - Watson (DW) coefficient reached (1.40), meaning that the model is appropriate and statistically significant, where it cannot be judged that there is an autocorrelation problem or (Systematic Error). 
3- Testing the forecasting ability of the first model:

We can test the viability of the model and its forecasting ability for current deposits in Jordanian banks by using dispersion factor standard (variance proportion) as in the following form:

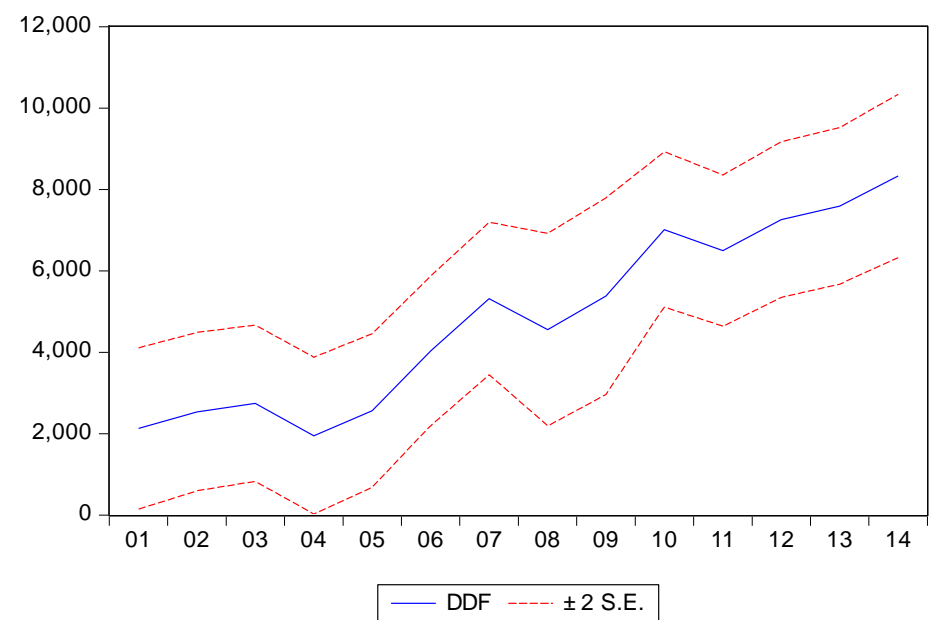

Forecast: DDF

Actual: DD

Forecast sample: 20002014

Adjusted sample: 20012014

Included observations: 14

Root Mean Squared Error

Mean Absolute Error

Mean Abs. Percent Error

Theil Inequality Coefficient

Bias Proportion

Variance Proportion

Covariance Proportion
741.9189

611.8763

17.10383

0.069571

0.000000

0.028012

0.971988

Figure 1. testing the forecasting ability of the model

Source: prepared by researchers with the help of the E-views program.

It is noticed that the model has an acceptable forecasting ability, and this is through Theil_ coefficient, as it is noticed that it is close to zero, where it was estimated at ( .06) suggesting that the model's forecasting ability of current deposits in banks is acceptable.

\section{- Discussing Hypotheses Based on the First Standard Model:}

The First hypothesis: there is a statistically significant, negative correlation between inflation rate and current deposits in Jordanian banks.

Through the standard estimate of the model, it is clear the value of the inflation rate coefficient (INF) equals (106.7880), a positive signal, which means that the correlation between the change in inflation rate and the change in current deposits is positive, and it is inconsistent with the economic and financial literature, which confirms the existence of a negative correlation between inflation rate on current deposits, but the reality of the actual performance during the study period (2000-2014) shows a positive correlation.

The reason may be that a high inflation rate will create a state of fear among the fund holders over directing their money towards investment in financial and real assets of various types (stocks, bonds, gold, land, buildings, equipment, vehicles, ...... etc), and rather directing it towards current deposit accounts, that are considered more liquid and less risky compared to the financial and real assets.

According to the $\mathrm{T}$-Test, this result is statistical significant at the (10\%) .the confidence level for this variable is equal to $(90 \%)$ which indicates the reject of hypothesis, there is a statistically significant, negative correlation between inflation rate and current deposits in Jordanian banks

The second hypothesis: there is a statistically significant, positive correlation between economic growth rate and current deposits in Jordanian banks .

Through the standard estimate of the model, it is clear that the value of the economic growth rate coefficient (GDPG) equals (-181.9374), a minus signal, which means that the correlation between the change in the economic growth and the change in the current deposits is negative and inconsistent with the economic and financial literature, which emphasizes that there is a positive correlation between economic growth and current deposits. But the reality of the actual performance during the study period (2000-2015) shows a negative correlation.

The reason may be that economic growth leads to a rise in economic activity. Therefore, the depositors convert their money from saving operations to various investment activities, due to higher sales and profits in the case of economic growth. 
According to the $\mathrm{T}-\mathrm{Test}$, this result is statistical significant at the ( $1 \%$ ) .the confidence level for this variable is equal to $(99 \%)$ which indicates the reject of hypothesis, there is a statistically significant, positive correlation between economic growth rate and current deposits in Jordanian banks

The third hypothesis: There is a statistically significant positive correlation between remittances of overseas workers and current deposits in Jordanian banks.

Through the standard estimate of the model, it is clear that the value of remittances of overseas workers coefficient (REM) equals (5.859653), a positive signal, which means that the correlation between remittances of overseas workers and the change in the current deposits is positive and is consistent with the economic and financial literature, and this was confirmed by the reality of the actual performance during the study period (2000-2015).

According to the $\mathrm{T}-\mathrm{Test}$, this result is statistical significant at the (1\%) .the confidence level for this variable is equal to $(99 \%)$ which indicates the acceptance of hypothesis, There is a statistically significant positive correlation between remittances of overseas workers and current deposits in Jordanian banks

- Estimating and Assessing the second regression model: the multiple linear regression method was used to estimate the impact of the independent variables on saving deposits (SD) in Jordanian banks, with the help of the (E-views) program. The results of the estimation were as following:

First, Estimating the second regression model

Table 2. The results of Estimating the second multi-model regression

\begin{tabular}{llll}
\hline Variable & Coefficient & t- Statistic & Prob. \\
\hline$\Delta$ INF & 52.90188 & 2.012263 & 0.0719 \\
GDPG & -90.60098 & -3.788719 & 0.0036 \\
REM & 2.483284 & 8.687856 & 0.0000 \\
C & -1357.718 & -2.599226 & 0.0265 \\
\hline
\end{tabular}

According to Table (2), the results of estimating the regression model were as following:

Adjusted R-Squared:\% $84 \quad$ R-Squared: $=\% 88 \quad$ F $=25 \quad$ D-W $=1.32 \quad \mathrm{n}=16$

Of the table (2) above, we note that the independent variable (INF) is significant at the significance level of $10 \%$. The two variables (GDPG, REM) are significant at significance level of 5\% .

The estimating equation for the second model is :

\section{SD $=\mathbf{- 1 3 5 7 . 7 1 8}+\mathbf{5 2 . 9 0 1 8 8 \Delta ~ I N F}-\mathbf{9 0 . 6 0 0 9 8}$ GDPG + 2.483284 REM}

\section{Second: Assessing the second regression model}

1. Assessing the model according to economic criteria: through the second column of Table (2) (Coefficient), which contains the assessed values of parameters, it comes clear that:

- The value of fixed (C) equals $(-1,357.718)$, the self-assessed signal of the saving deposits is minus.

- The value of the inflation rate coefficient (INF) equals (52.90188), a positive signal, which is inconsistent with the economic and financial literature.

- The value of the economic growth rate coefficient (GDPG) equals (-90.60098), a minus signal, which is inconsistent with the economic and financial literature.

- The value of remittances of overseas workers coefficient (REM) equals (2.483284), a positive signal, which is consistent with the economic and financial literature.

2- Assessing the model according to the statistical standard

According to the model, the coefficient of determination is (Adjusted R- Squared: 84\%), which means that changes in the independent variables together explain about $(88 \%)$ of the changes in the dependent variable. While the value of (F-statistic ) reached (25), and reached zero at Prob significance level, meaning that this model is statistically significant.

The Darben - Watson (DW) coefficient reached (1.32), meaning that the model is appropriate and statistically significant, where it cannot be judged that there is self-correlation problem or (Systematic Error). 
3- Testing the forecasting ability of the second model

We can test the viability of the model and its forecasting ability of saving deposits in Jordanian banks using dispersion factor standard (variance proportion), as following:

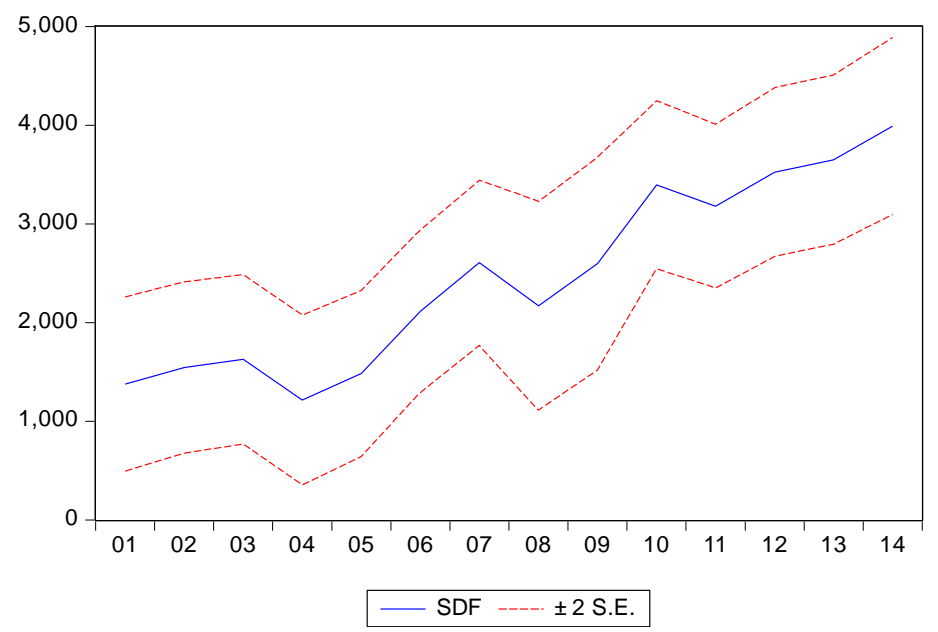

\begin{tabular}{|ll|}
\hline Forecast: SDF \\
Actual: SD \\
Forecast sample: 20002014 \\
Adjusted sample: 20012014 \\
Included observations: 14 \\
Root Mean Squared Error & 331.1768 \\
Mean Absolute Error & 275.0277 \\
Mean Abs. Percent Error & 13.84656 \\
Theil Inequality Coefficient & 0.062801 \\
$\quad$ Bias Proportion & 0.000000 \\
Variance Proportion & 0.030728 \\
Covariance Proportion & 0.969272 \\
\hline
\end{tabular}

Figure 2. testing the forecasting ability of the model

Source: prepared by researchers with the help of the E-views program

It is noticed that the model has an acceptable forecasting ability, and this is through the Theil coefficient, as it is noticed that it is close to zero, where it was estimated at ( 0.06) indicating that the forecasting ability of the model of saving deposits in Jordanian banks is acceptable.

\section{- Discussing hypotheses based on the second standard model}

The Fourth hypothesis: There is a statistically significant, negative correlation between inflation rate and saving deposits in Jordanian banks.

The standard estimate of the model has shown that the value of the inflation rate coefficient (INF) equals (52.90188), a positive signal, which means that the correlation between the change in the inflation rate and the change in the saving deposits is positive, which is inconsistent with the economic and financial literature, that confirms the existence of a negative correlation between inflation rate and saving deposits, but the reality of the actual performance during the study period (2000-2015) indicates a positive correlation.

The reason behind that is that most of the owners of the saving deposits are small savers with limited income. They most likely do not have necessary information, expertise or proofs about economically-viable investment fields, which their revenue overweighs saving deposits revenue, which push them to increase demand for saving deposits.

According to the $\mathrm{T}-\mathrm{Test}$, this result is statistical significant at the (10\%) .the confidence level for this variable is equal to $(90 \%)$ which indicates the reject of hypothesis, There is a statistically significant, negative correlation between inflation rate and saving deposits in Jordanian banks

The Fifth hypothesis: There is a statistically significant, positive correlation between economic growth rate and saving deposits in Jordanian banks.

The standard estimate of the model showed that the value of economic growth coefficient (GDPG) equals (-90.60098), a minus signal, which means that the correlation between the change in the economic growth and the change in saving deposits is negative, which is inconsistent with the economic and financial literature, that confirms the existence of a positive correlation between growth economic and saving deposits, but the reality of the actual performance during the study period (2000-2015) indicates a negative correlation.

The reason is that the economic growth leads to a rise in the economic activity, thereby convert savings into investment due to higher sales and profits in the case of economic growth.

There is a statistically significant, negative correlation between inflation rate and saving deposits in Jordanian banks 
According to the $\mathrm{T}-\mathrm{Test}$, this result is statistical significant at the (1\%) .the confidence level for this variable is equal to $(99 \%)$ which indicates the reject of hypothesis ,There is a statistically significant, positive correlation between economic growth rate and saving deposits in Jordanian banks

The Sixth hypothesis: There is statistically significant, positive correlation between remittances of overseas workers and saving deposits in Jordanian banks.

The standard estimate of the model showed that the value of remittances of overseas workers' coefficient (REM) equals (2.483284), a positive signal, which means that the correlation between remittances of overseas workers and the change in the saving deposits is positive, which is consistent with the economic and financial literature, as confirmed by the reality of the actual performance during the study period (2000-2015).

According to the $\mathrm{T}-\mathrm{Test}$, this result is statistical significant at the (1\%) .the confidence level for this variable is equal to $(99 \%)$ which indicates the acceptance of hypothesis, There is statistically significant, positive correlation between remittances of overseas workers and saving deposits in Jordanian banks.

-Estimating and Assessing the second regression model: the multiple linear regression method was used to estimate the impact of the independent variables on time deposits (TD) in Jordanian banks, with the help of the (E-views) program. The results of the estimate were as following:

\section{First, Estimating the third regression model}

Table 3. The results of estimating the third multiple regression model

\begin{tabular}{llll}
\hline Variable & Coefficient & t- Statistic & Prob. \\
\hline$\Delta$ INF & 129.6900 & 2.225801 & 0.0502 \\
GDPG & -228.3537 & -4.308575 & 0.0015 \\
REM & 9.791017 & 15.45540 & 0.0000 \\
C & -5738.621 & -4.956876 & 0.0006 \\
\hline
\end{tabular}

According to Table (3), The results of estimating the regression model were as following:

Adjusted R-Squared:\% $94 \quad$ R-Squared: $=\% 96 \quad \mathrm{~F}=80 \mathrm{D}-\mathrm{W}=2.21 \quad \mathrm{n}=15$

Of the table (3) above, we note that the independent variable (INF) is significant at the significance level of $10 \%$. While the two variables (GDPG, REM) were significant at the significance level of 5\%.

\section{The estimating equation for the third model}

TD = -5738.621 + 129.6900 $\Delta$ INF -228.3537 GDPG +9.791017 REM

\section{Second, Assessing the third regression model}

1- Assessing model according to economic standard: through the second column of the table (3) (Coefficient), which contains the estimated values of parameters, it comes clear that:

- The value of the fixed (C) equals $(-5,738.621)$, the self-estimated signal for time deposits is minus.

- The value of the inflation rate coefficient (INF) equals (129.6900), a positive signal, which is inconsistent with the economic and financial literature.

- The value of the economic growth rate coefficient (GDPG) equals (-228.3537), a minus signal, which is inconsistent with the economic and financial literature.

- The value of remittances of overseas workers' coefficient (REM) equals (9.791017), a positive signal, which is consistent with the economic and financial literature.

2- Assessing the model according to the statistical standard

Through the model, it is clear that the Adjusted interpretation coefficient is (Adjusted R-Squared:\% 94), which means that changes in the independent variables together explain about (96\%) of the changes in the dependent variable.

While the value of (F-statistic ) reached (80), and reached zero at the Prob significance, which means that the model is statistically significant. The Darben - Watson (DW) coefficient reached (2.15), which means that the model is appropriate and statistically significant, where it cannot be judged that there is a self-correlation problem or (Systematic Error). 
3- Testing the forecasting ability of the third model

We can test the viability of the model and its forecasting ability of time deposits in Jordanian banks using the standard dispersion factor (variance proportion) as in the following form:

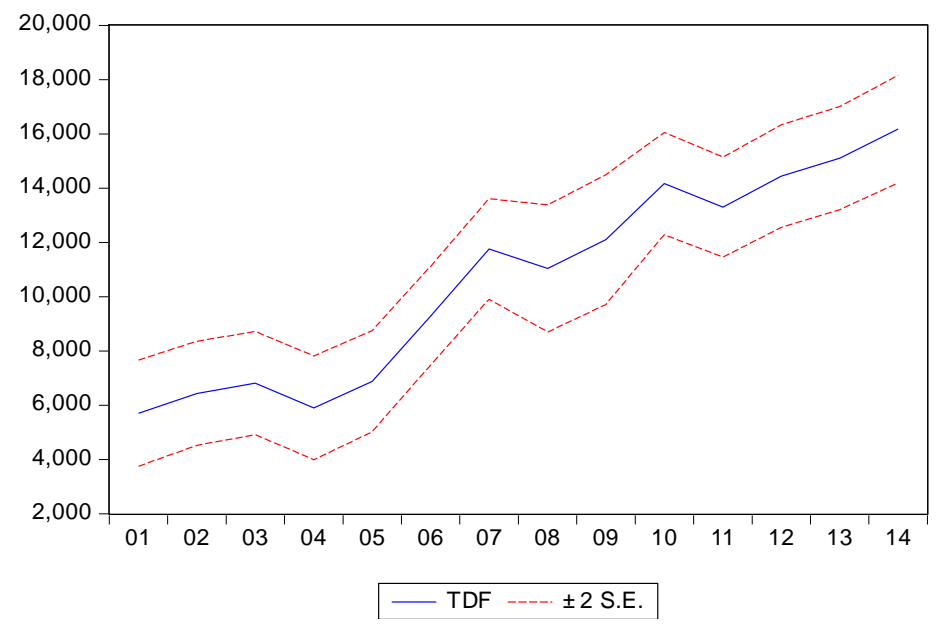

\section{Forecast: TDF}

Actual: TD

Forecast sample: 20002014

Adjusted sample: 20012014

Included observations: 14

Root Mean Squared Error 733.9961

Mean Absolute Error $\quad 636.9373$

Mean Abs. Percent Error $\quad 6.548268$

Theil Inequality Coefficient $\quad 0.032599$

Bias Proportion $\quad 0.000000$

Variance Proportion $\quad 0.010086$

Covariance Proportion $\quad 0.989914$

Figure 3. Testing the ability of the model to forecast

Source: prepared by researchers with the help of the E-views program

It is noticed that the model has an acceptable forecasting ability, and that is through the Theil coefficient, noting that it is close to zero, where it was estimated at (0.03) indicating that the forecasting ability of the model of time deposits in Jordanian banks is acceptable.

\section{Discussing hypotheses based on the third standard model}

The Seventh hypothesis: there is a statistically significant, negative correlation between inflation rate and time deposits in Jordanian banks.

Through the standard estimate of the model, it is clear that the value of the inflation rate coefficient (INF) equals (129.6900), a positive signal, which means that the correlation between the change in the inflation rate and the change in time deposits is positive, and that is inconsistent with the economic and financial literature, that confirms the existence of a negative correlation between inflation rate and time deposits.

However, the reality of the actual performance during the study period (2000-2015) indicates a positive correlation. The reason for that may be the state of uncertainty and pessimism about the future, which may prevail under inflationary environment characterized by confusion, and instability in the production process.

According to the $\mathrm{T}$-Test, this result is statistical significant at the ( $1 \%$ ) .the confidence level for this variable is equal to $(99 \%)$ which indicates the reject of hypothesis ,there is a statistically significant, negative correlation between inflation rate and time deposits in Jordanian banks

The Eighth hypothesis: There is a significant positive correlation between economic growth rate and time deposits in Jordanian banks.

The standard estimate of the model showed that the value of economic growth coefficient (GDPG) equals (-228.3537), a minus signal, which means that the correlation between the change in the economic growth and the change in time deposits is negative, which is inconsistent with the economic and financial literature, which confirms the existence of a positive correlation between growth economic and time deposits. But the reality of the actual performance during the study period (2000-2015) indicates a negative correlation.

The reason is that in the case of economic growth, economic activity increases, and therefore, money holders prefer exploiting their money in various investment operations rather than depositing them as time deposits, due to higher sales and profits in the case of economic growth.

According to the $\mathrm{T}$-Test, this result is statistical significant at the ( $1 \%$ ) .the confidence level for this variable is equal to $(99 \%)$ which indicates the reject of hypothesis, There is a significant positive correlation between economic growth rate and time deposits in Jordanian banks

The Ninth hypothesis: There is a statistically significant, positive correlation between remittances of overseas workers and time deposits in Jordanian banks. 
The standard estimate of the model shows that the value of remittances of overseas workers' coefficient (REM) equals (9.791017), a positive signal, which means that the correlation between remittances of overseas workers and the change in the time deposits is positive, which is consistent with the economic and financial literature. And this was confirmed by the reality of the actual performance during the study period (2000-2015).

According to the $\mathrm{T}-\mathrm{Test}$, this result is statistical significant at the (1\%) .the confidence level for this variable is equal to $(99 \%)$ which indicates the acceptance of hypothesis, There is a statistically significant, positive correlation between remittances of overseas workers and time deposits in Jordanian banks.

\section{Results of the Study}

Results of the Study can be summarized in the following points:

1- The largest share of the size of deposits in Jordanian banks was for the time accounts by $(72.1 \%)$ of the total in 2000 , and $(55.5 \%)$ in 2015. While demand deposit accounts gained (16\%) of the total 2000 and $(5.30 \%)$ in 2015. While the share of saving deposit accounts reached (8.11\%) in 2000 and (14\%) in 2015.

2 - There is a statistically significant positive correlation between the inflation rate and current deposits. The reason is that high inflation rate will create a state of fear among the fund holders over investing their money in real and financial assets, such as (stocks, bonds, gold, land, buildings, equipment, vehicles, ..... etc.), which pushes them to direct their money towards current deposit accounts, which are more liquid and less risky compared to the financial and real assets.

3- There is a statistically significant negative correlation between economic growth rate and current deposits. The reason is that economic growth leads to increased economic activity, therefore, the depositors convert their money from saving operations to various investment activities, due to higher sales and profits in the case of economic growth.

4- There is a statistically significant positive correlation between the remittances of overseas workers and current deposits, which means that these remittances play a positive role in the development of current deposits in Jordan.

5- There is a statistically significant positive correlation between inflation rate and saving deposits. The reason is that most of the owner of the saving deposits are small savers with limited income. They most likely do not have necessary information, the expertise or proofs, about economically-viable investment fields, which their revenue outweighs the revenue of the saving deposits, which drives them to increase demand for saving deposits.

6- There is a statistically significant negative correlation between economic growth rate and saving deposits. And this means that the economic growth rate leads to increased saving deposits in Jordan, and the reason is that the economic growth leads to increased economic activity, subsequently, convert saving into investment, due to higher sales and profits in the case of economic growth.

7- There is a statistically significant positive correlation between remittances of overseas workers and saving deposits, which means these remittances play a positive role in the development of saving deposits in Jordan.

8- There is a statistically significant positive correlation between the inflation rate and time deposits. The reason is the state of uncertainty and pessimism about the future, which may prevail under inflationary environment characterized by confusion and instability in the production process.

9- There is a statistically significant negative correlation between economic growth rate and time deposits, which means that the economic growth rate leads to increased time deposits in Jordan. The reason is that in the case of economic growth, economic activity increases, therefore, money holders prefer to exploit their money in various investment operations rather than depositing them as time deposits, due to higher sales and profits in the case of economic growth.

10- There is a statistically significant positive correlation between remittances of overseas workers and time deposits, this means that these remittances play a positive role in the development of time deposits in Jordan.

\section{Recommendations}

In light of the results, the study recommends the following:

1- The need for local banks administration to take into consideration the economic factors and variables, including inflation, economic growth and remittances of overseas workers, which directly affect the bank deposits in Jordan, in addition to study their evolution and forecast their value in future periods; to take various measures that would be positively reflected on the growth of bank deposits. 
2- The need for local banks administration to attract more remittances of overseas workers, through genuine and honest programs that provide benefits for workers abroad and the bank alike.

3- Provide new and innovative features to depositors, such as providing insurance feature on time deposits among other advantages, in order to urge depositors to deposit their money in this kind of deposit, which contributes in providing the necessary funding for local real investment.

4- Establishing specialized departments for banking guidance, as well as increasing advertising and promotional campaigns using creative ways to introduce the public with the advantages and benefits that can be gained from the deposit process.

5- Finding saving instruments in commercial banks that are developed more than the current ones, such as investment accounts in Islamic banks.

6- Proposing making further applied studies at the local level about the factors affecting bank deposits, particularly economic ones, such as: government spending, accumulation of capital, exchange rate and disposable income.

\section{References}

Adam, Mohammed Abdullah Abdul Rahman. (2012). Demand function for Bank Deposits in Sudan. Master thesis, Khartoum: Sudan University of Science and Technology, Business Studies department.

Al-Gazaw, Abdul Wahab Ahmed. (2013). The impact of Remittances of Jordanian abroad on the Jordanian economy. Master thesis, Jordan, Yarmouk University, Faculty of Economics and Administrative Sciences. 1.

Al-Jabali, Abdel Fattah. (2016). an article entitled: Encouraging domestic saving...... an absent ordinance, Al-Ahram magazine, November 8, 2016, year 141, no. 47454.

Alman, Mohammad Sharif. (2010). lectures in macroEconomic theory, the office of University publications, Part 3, 2nd Floor, Algeria 0.2010, 30.

Al-Zubaidi, Hamza Mahmoud. (2000). the Bank management: mobilizing Deposits and providing credit strategy, Oman, Warraq for Publishing and Distribution, 159.

Erna Rachmawati \& Ekki Syamsulhakim. (2004). Factors Affecting Mudaraba Deposits in Indonesia. Working Paper in Economics and Development Studies. Padjadjaran University of Indonesia.

Hamad, Alaa Mohamed Masoud. (2009). the impact of monetary policy on interest rates in commercial banks of Jordan. Master thesis, Jordan, Aal-Bayt University, Business and Finance Management department.

John H. Boyd, Ross Levine, \& Bruce D. Smith. (2001). The Impact of Inflation on Financial Sector Performance. Journal of Monetary Economics, 47, 221-48.

Marar, Rabih. (2016). analysis of the links between the macro-banking indicators and the Economic growth at the macro and sectoral levels in occupied Palestine, Palestine Economic Policy Research Institute (MAS), 3.

Mashharawi, Ahmed Hussain Ahmed. (2007). the impact of the financial position variables in Islamic banks' profitability for the period 1996-2007. Master thesis, Gaza, Islamic University, 59.

Ojeaga, Paul and Odejimi, Omosefe. (2014). The Impact of Interest Rate on Bank Deposit: Evidence from the Nigerian Banking Sector. Mediterranean Journal of Social Sciences, 5(16), 232-238.

Otu Larbi-Siaw, Peter Angmor Lawer. (2015). Determinants of Bank Deposits in Ghana: A Cointegration Approcah. Asian Journal of Economics and Empirical Research, 2(1), 1-7.

Rafiee, S \& Neghabi, Z. (2013). An investigation on different factors influencing growth of banking Deposits. Management Science Letters, 3(1), 195-200.

Saeed, Abdul Salam laftah. (2006). Analysis of Bank Deposits, proposed form. Baghdad Journal of Baghdad College of Economic Sciences, edition no. 11, 2006.

Saydam, Mahmoud. (2007). a report on the Remittances of Jordanians abroad. Amman Chamber of Commerce, studies and training management, studies and international agreements units.

The central bank of Jordan, various editions. (2000-2015).

Valahzaghard, M \& Kashfi, S .(2014.) Investigating the effects of various factors on Bank Deposits. Management Science Letters, 4(4), 707. 